\title{
Overzealous Women's Health Screening? My Story
}

\author{
Rani Marx, PhD, MPH(1)
}

Initiative for Slow Medicine, Berkeley, CA, USA.

J Gen Intern Med 36(9):2825-6

DOI: $10.1007 / \mathrm{s} 11606-020-06335-7$

(c) Society of General Internal Medicine 2020

$\mathrm{F}$ or decades, my yearly gynecology check-ups included pelvic exams, PAP smears, and breast exams. In my mid-forties, my primary care physician strongly recommended annual mammograms. Around that time, I started getting annual ultrasounds of a small ovarian cyst, an incidentaloma detected via an unrelated MRI. I have no risk factors for breast, ovarian, or cervical cancer.

I am sixty now and, until recently, battled overwhelming clinician insistence on more screening than indicated by the medical literature, screening that might do me more harm than good. Besides being a patient, I am an epidemiologist and conducted primary care evaluations for 12 years.

Initially I accepted screenings ordered by my primary care doctors and gynecologists, but gradually questioned the advisability of these tests. Scientific literature at the time and exchanges with colleagues suggested annual screenings were overzealous. When I attempted to discuss identified risks and benefits with my clinicians and proffered references, it fell on deaf ears. Both my primary care doctor and gynecologist stated they "wouldn't want to miss anything" and invariably related an anecdote about a patient whose early cancer would have been missed absent these screenings. It was awkward going up against them; I did not want to be a difficult patient. And they wore me down. Despite my knowledge, I felt a niggling sense of worry. What if I was one of the very few who developed disease because I wasn't screened? I gave in, but was upset with myself each time.

While the annual screenings might seem harmless enough, several experiences and the literature say otherwise. The ovarian ultrasounds were uncomfortable: considerable pressure was exerted on my abdomen to image the cyst adequately. I waited anxiously to hear if the cyst had grown or changed. It was stable for years, and then decreased in size. My gynecologist repeatedly offered to remove it, a brief surgery he conducted weekly. I asked about the probability the cyst was malignant. Though he deemed this highly unlikely, he said

Received October 2, 2020

Accepted October 21, 2020

Published online November 4, 2020 he could easily remove it so I'd be free from worry. I did worry, but not enough to have it removed. All surgical procedures carry some risk and I read that some women getting this "simple" surgery suffer from surgical adhesions and resulting chronic pain. A recent definitive study reinforces that simple cysts are unassociated with ovarian cancer and do not require repeated imaging, carrying associated morbidity. ${ }^{1}$

My annual PAP smears were occasionally uncomfortable and always unsettling. Years before, I had been scared by one abnormal PAP; it was normal when repeated. For at least half of those 14 years, United States Preventive Services Task Force (USPSTF) guidelines clearly indicated I should receive a PAP every 3 years. ${ }^{2}$ When I questioned my gynecologist, he stated he liked to do them annually. In fact, he collected the sample as part of the pelvic exam without asking me. I always awaited the lab results with trepidation.

My annual mammograms were painful and troubling. The specter of breast cancer is incredibly frightening for any woman. I have friends, colleagues, acquaintances, and family who have died of breast cancer. Since mammography was widely encouraged in the 1980s, breast cancer incidence has increased significantly but mortality has not, a clear indication of overscreening. ${ }^{3}$ Based on evidence of risks and benefits, in 2014 the Swiss Medical Board recommended no new mammography screening programs and a reevaluation of existing programs. ${ }^{4}$

My mammograms always hurt: breasts aren't meant to be pulled and squashed between heavy metal plates. According to the literature, the advantages of annual screening beginning in my mid-forties did not outweigh the risks. The prevalence of false positives and avalanche of procedures and interventions that often ensue were not factored into my care. Whenever I raised the issue, out came the anecdotes. Several times I had my mammogram repeated to assess a questionable finding.

A women's health center conducted my mammograms. They were always peddling some enhanced mammography not "yet" covered by insurance that involved out-of-pocket costs. It was a hard sell. Multiple staff suggested the procedure and glossy brochures touted the advantages. I succumbed to several of these "offers." Discomfort could be extreme. One inept technician caused me 2 weeks of pain. Unusual "findings" generated great anxiety. Five years ago, a routine mammogram revealed microcalcifications in one breast. I was told to return in 6 months for another mammogram with enhanced magnification. According to the literature, microcalcifications are common and usually benign, but those 6 months were 
tension provoking. At follow-up, the radiologist came to speak with me. Greater magnification revealed several additional microcalcifications. He assured me they were most likely benign but might be malignant, and offered to remove them via needle biopsy, mentioning some women find the procedure quite painful. My lab report stated there was a less than $10 \%$ chance of ductal carcinoma in situ. I requested statistics on false positives and the risks of doing nothing. He had none but stated this was a new finding for me. I returned home and unearthed my previous mammograms. A routine mammogram the prior year with normal magnification revealed microcalcifications in the same breast. Still uncertain how to proceed, I consulted my primary care physician. She said it was my decision and declined to weigh in or provide information. I decided to do nothing.

Several months ago, I began receiving reminders to schedule my annual mammogram. I rechecked the USPSTF recommendation for biennial rather than annual screening ${ }^{5}$ and read a modeling study that confirmed I should be screened biennially and had already far exceeded the recommended lifetime number of mammograms. ${ }^{6}$

Tired of feeling railroaded and the lack of an evidencebased public health approach to my private health, I finally switched to a new primary care doctor and gynecologist.

A few weeks ago, I consulted on Zoom with this gynecologist, in a new medical group. She confirmed that a biennial mammogram and a PAP smear in 4 years (it can be my last) is appropriate, and wondered why my cyst had been imaged annually. She also informed me there was no benefit to annual pelvic exams; for the past 6 years, mine had been unnecessary. $^{7}$

I felt tremendous relief, but was also angry about the distress, discomfort, and anxiety I should have been spared and the inability of my physicians to thoughtfully discuss my options, weighing my needs and desires in the context of known risks. Women are misinformed about screening risks (e.g., for mammography) and thus cannot properly weigh them. ${ }^{4}$

Physicians operate in health plans with policies that contradict the best available science. Guidelines can diverge. Many patients pressure physicians for more rather than less screening and intervention. Doctors can face liability issues if they intervene less. Doctors and patients are not oriented toward population health, acting based on what they perceive to be best for the individual. And there is the financial incentive to do more, a major driver of our insurance system. But surely harm to the patient, both psychological and physical, should be considered before ignoring scientific evidence of best practices, and certainly patient wishes should be solicited and honored. Women should be systematically informed of evidence-based screening recommendations, and insurers should remove financial incentives for physicians to override best practices.

Corresponding Author: Rani Marx, PhD, MPH; Initiative for Slow Medicine, Berkeley, CA, USA (e-mail: ranimarx1960@gmail.com).

\section{Compliance with Ethical Standards:}

Conflict of Interest: The author has no conflict of interest.

\section{REFERENCES}

1. Smith-Bindman R, Poder L, Johnson E, Miglioretti DL. Risk of Malignant Ovarian Cancer Based on Ultrasonography Findings in a Large Unselected Population. JAMA Intern Med. 2019;179(1):71-77. https://doi. org/10.1001/jamainternmed.2018.5113

2. US Preventive Services Task Force. Screening for Cervical Cancer: US Preventive Services Task Force Recommendation Statement. JAMA. 2018;320(7):674-686. https://doi.org/10.1001/jama.2018.10897

3. Welch HG, Kramer BS, Black WC. Epidemiologic Signatures in Cancer. N Engl J Med. 2019;381(14):1378-1386. https://doi.org/10.1056/ NEJMsr 19054474.

4. Biller-Andorno N, Jüni P. Abolishing mammography screening programs? A view from the Swiss Medical Board. N Engl J Med. 2014;370(21):19651967. https://doi.org/10.1056/NEJMp1401875

5. Siu AL. U.S. Preventive Services Task Force. Screening for Breast Cancer: U.S. Preventive Services Task Force Recommendation Statement [published correction appears in Ann Intern Med. 2016 Mar 15;164(6):448]. Ann Intern Med. 2016;164(4):279-296. https://doi.org/10.7326/M152886

6. Trentham-Dietz A, Kerlikowske $\mathbf{K}$, Stout NK, et al. Tailoring Breast Cancer Screening Intervals by Breast Density and Risk for Women Aged 50 Years or Older: Collaborative Modeling of Screening Outcomes. Ann Intern Med. 2016;165(10):700-712. https://doi.org/10.7326/M16-0476

7. Gaseem A, Humphrey LL, Harris R, Starkey M, Denberg TD. Clinical Guidelines Committee of the American College of Physicians. Screening pelvic examination in adult women: a clinical practice guideline from the American College of Physicians. Ann Intern Med. 2014;161(1):67-72. https://doi.org/10.7326/M14-0701

Publisher's Note: Springer Nature remains neutral with regard to jurisdictional claims in published maps and institutional affiliations. 